\title{
In-situ observation of stress accumulation during sub-merged arc welding
}

\author{
Arne Kromm ${ }^{1, a *}$ and Thomas Kannengiesser ${ }^{1, b}$ \\ ${ }^{1}$ BAM Federal Institute for Materials Research and Testing, Unter den Eichen 8712205 Berlin, \\ Germany \\ aarne.kromm@bam.de, ${ }^{b}$ thomas.kannengiesser@bam.de
}

Keywords: sub-merged arc welding, heat control, bending moments, X-ray diffraction

\begin{abstract}
Results obtained from laboratory tests mostly need to be verified under fabrication conditions in order to incorporate design specifics (joint configuration and restraint), which effect the residual stress state considerably. For this purpose, multi-pass sub merged arc welding was performed in a special large-scale testing facility. The impact of varying interpass temperatures could be proven in-situ by means of a pronounced stress accumulation during welding and subsequent heat treatment accompanied by stress determination using X-ray diffraction.
\end{abstract}

\section{Introduction}

Especially when welding high strength steels, attention has to be paid to the residual stresses. Knowledge gained from studies made in the past rather concern residual stress characteristics found in welds representing samples on the laboratory scale, neglecting size effects. Especially in thickwalled joints, the ratio of the heat affected area to the material which remains cold becomes small, representing a high degree of restraint. Additionally, high stiffness or surrounding structures may increase the residual stress level [1-3].

In general the residual stress state of a welded structure is affected by the interaction of mechanical, thermal and material factors. The local stresses in welded joints can be described in simplified terms as a superposition of three single factors due to inhomogeneous temperature distributions in weld and HAZ, i.e. shrinkage stresses, quenching stresses and transformation stresses. In practice, the superposition of these three factors results in characteristic residual stress distributions controlled by the dominating effect in each case [4-5].

Furthermore, welding process parameters (e.g. heat control or number of weld passes) can influence the residual stress level considerably [6-10]. However, due to the complex interrelationship of the above stated factors in most cases neither the final residual stress level nor its distribution can be predicted a priori. As the modelling effort in case of large structures may become inefficient, component tests are indispensable. Within in the present study a component weld test was performed in a special large-scale test facility. The heat control was varied by applying two different interpass temperatures in order to examine their influence on the reaction stresses and the local residual stresses. Special attention was paid to occurring bending moments, which result from excentric forces acting in thick-walled joints, but have not been investigated adequately up to the present.

\section{Experimental}

Submerged arc narrow-gap welding was conducted on high strength base material A508 with a thickness of $47 \mathrm{~mm}$. Plates with a length of $480 \mathrm{~mm}$ and a width of $150 \mathrm{~mm}$ were selected to reproduce geometries close to real fabrication. Run-on and run-off tabs were used to ensure a constant weld cross section along the weld. The mechanical properties of the steel are shown in Table 1. A flux-cored filler wire with a diameter of $2.4 \mathrm{~mm}$ was used in combination with fluoride basic flux (SA FB 155 AC) according to the European standard EN 760. This wire/flux combination ensured a strength $>400 \mathrm{MPa}$ in the untreated condition. A schematic of the joint geometry is shown in Fig. 1. 
Table 1: Mechanical properties of the base material

\begin{tabular}{cccc}
$\mathrm{R}_{\mathrm{m}}[\mathrm{MPa}]$ & $\mathrm{R}_{\mathrm{p} 0.2}[\mathrm{MPa}]$ & $\mathrm{A}_{5}[\%]$ & $\mathrm{Z}[\%]$ \\
\hline $620-795$ & 485 & 20 & 48
\end{tabular}

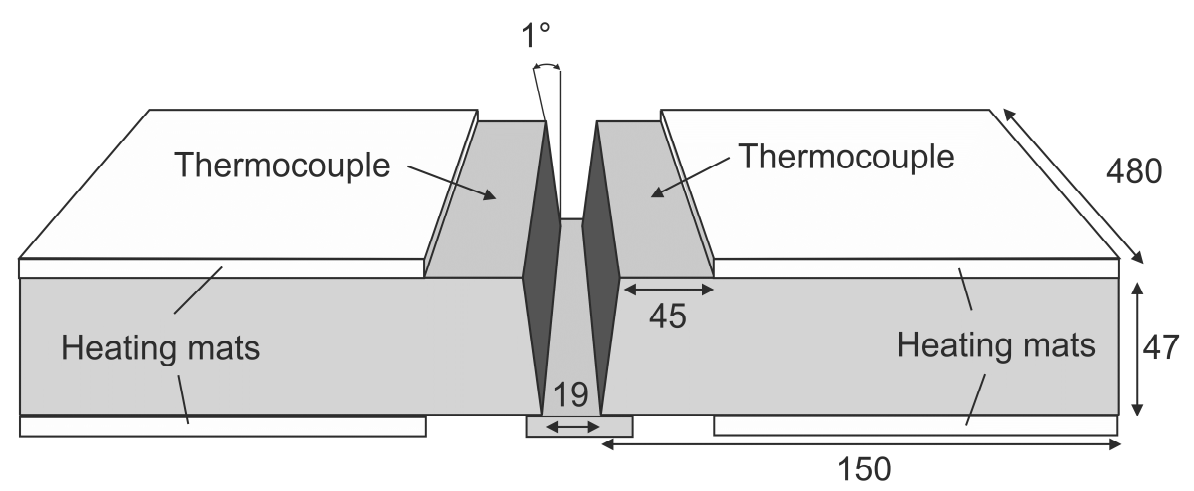

Fig. 1: Schematic of the joint configuration showing the position of the heating mats used for heat treatment

The parameters shown in Table 2 were kept constant for all test welds. Preheating and a post weld dehydrogenation heat treatment (DHT) $\left(4 \mathrm{~h}\right.$ at $\left.300^{\circ} \mathrm{C}\right)$ were conducted by heating mats applied on weld, heat affected zone (HAZ) and base material. DHT was chosen in order to reproduce realistic heat control. On the other hand possible risk of cracking in the weld or HAZ should be minimized. Thermocouples located in a distance of $50 \mathrm{~mm}$ from the weld on the top and bottom surface served for temperature control of preheating and DHT. Two different interpass temperatures $\left(150^{\circ} \mathrm{C}\right.$ and $\left.200^{\circ} \mathrm{C}\right)$ were applied, while the preheating temperature was kept constant at $150^{\circ} \mathrm{C}$. Welding was performed in 26 to 29 runs. With higher IPT the number of the weld passes was slightly decreased due to the higher amount of heat. The IPT was controlled by a contact thermocouple on the weld surface.

Table 2: Welding parameters

\begin{tabular}{l|l} 
Welding current $[\mathrm{A}]$ & $430 \mathrm{~A}$ \\
Welding voltage [34] & $34 \mathrm{~V}$ \\
Heat input E $[\mathrm{kJ} / \mathrm{mm}]$ & 2.0 \\
Travel speed $[\mathrm{mm} / \mathrm{s}]$ & 7.17 \\
Interpass temperature $\left[{ }^{\circ} \mathrm{C}\right]$ & Joint I: 150; Joint II: 200
\end{tabular}

For in-situ analysis of the occurring load during welding, DHT and subsequent cooling, a largescale test facility was used. The three-dimensional servo-hydraulically controlled system has a load capacity of up to $16 \mathrm{MN}$. It allows for online observation of the globally acting reaction force $\mathrm{F}_{\mathrm{y}}$ in weld transverse direction. For that purpose, the specimen is fixed between two movable crossheads located on a stiff frame, as schematically shown in Fig. 2. As the crossheads are position-controlled the weld sample is fully restrained (fixed position). The occurring reaction forces due to heat input and cooling are determined from strains measured in four piston rods. Furthermore, the bending moment around the neutral axis of the system can be determined from the force difference found between the upper and lower side. Table 3 shows some features of the large-scale test facility. The restraint intensity $\mathrm{R}_{\mathrm{Fy}}$ of the test system results from the stiffness of the frame divided by the weld length.

The local residual stresses were determined after cooling to ambient temperature using a mobile X-ray diffractometer. The restraint was still applied during the measurement. Using a step size of $5 \mathrm{~mm}$, the residual stresses were measured in transverse weld direction along a line covering the 
weld, the HAZ and the base material. The parameters for the residual stress determination are listed in Table 4. The $\sin ^{2} \psi$-technique was used for stress determination [11].

Table 3: Features of the large-scale test facility

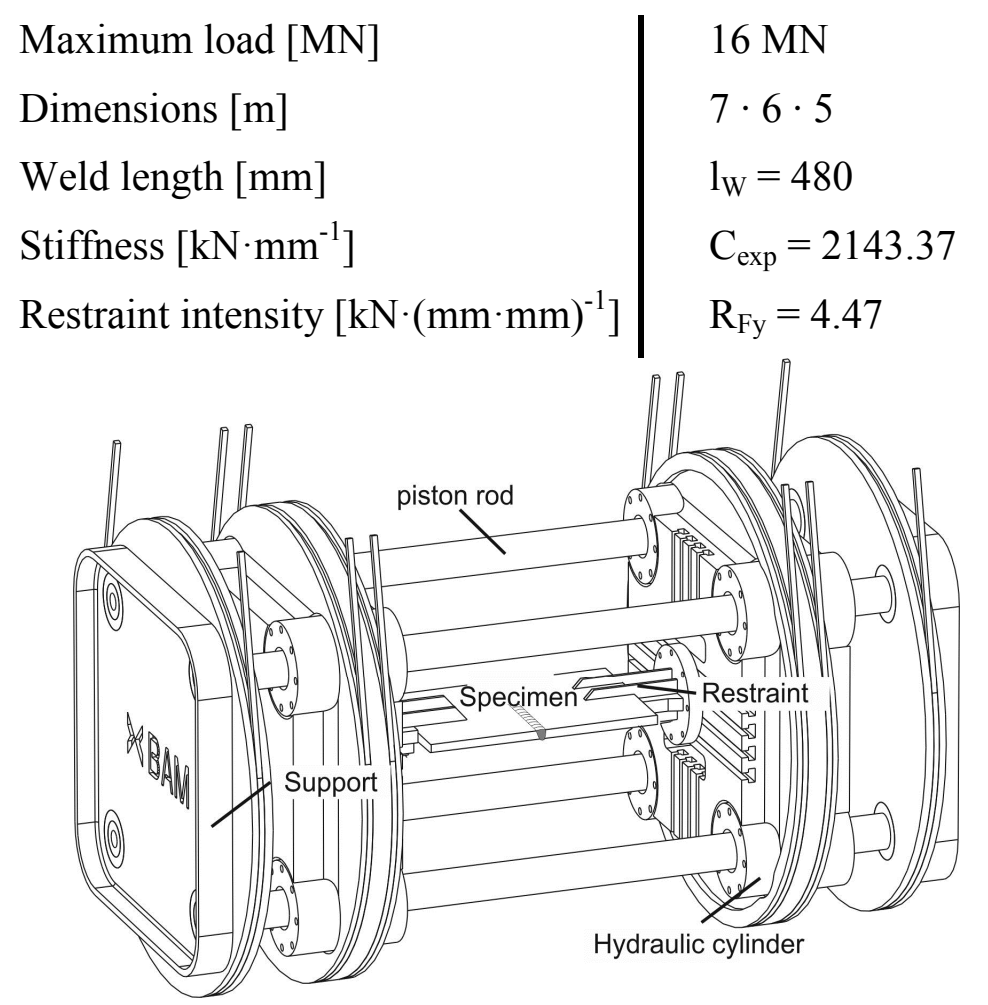

Fig. 2: Schematic of the large-scale test facility

Table 4: X-ray measuring and evaluation parameters

\begin{tabular}{l|l} 
Radiation & $\mathrm{CrK}_{\alpha}$ \\
Lattice plane (hkl) & Ferrite: 211 \\
Aperture [mm] & 3 \\
Exposure time [s] & 5 \\
E [MPa] & 211.000 \\
$\nu$ & 0.3 \\
$\psi$ range & $-45^{\circ}$ to $45^{\circ}$ in 10 steps
\end{tabular}

\section{Results}

Stress accumulation during welding - reaction force. The characteristics found for the reaction force are shown in Fig. 3 (left) for joint I $\left(\mathrm{IPT}=150^{\circ} \mathrm{C}\right)$ compared to joint II (IPT $=200^{\circ} \mathrm{C}$, right). During the first stage, i.e. welding of the individual passes, the forces were increased followed by an overall decrease during DHT. Finally, cooling to ambient temperature led to a steep increase of the forces. The force behaves inversely to the temperature shown on the right axis in Fig. 3. During welding the force is periodically decreased by the welding heat input and subsequently increased by the shrinkage to interpass temperature of each single run. In total the increase is higher than the overall decrease. As the cooling cycles for joint I are longer (lower IPT) higher force accumulation is observed here compared to joint II. In sum a reaction force of about $800 \mathrm{MPa}$ was registered for joint I $\left(\mathrm{IPT}=150^{\circ} \mathrm{C}\right.$ ), while joint II (IPT $=200^{\circ} \mathrm{C}$ ) shows less than $500 \mathrm{MPa}$ as a consequence of the welding cycle. 
Subsequent DHT was applied directly after the last pass has cooled to IPT. As can be seen from Fig. 3, the reaction forces were decreased during this stage to compressive values below $-500 \mathrm{kN}$ due to the heat input. No significant differences were found between both joints.

After applying the DHT the whole specimens cooled down to ambient temperature, what took about $24 \mathrm{~h}$. The forces followed the temperature curve inversely, ending with a final reaction force of around $2000 \mathrm{kN}$ for both joints investigated.
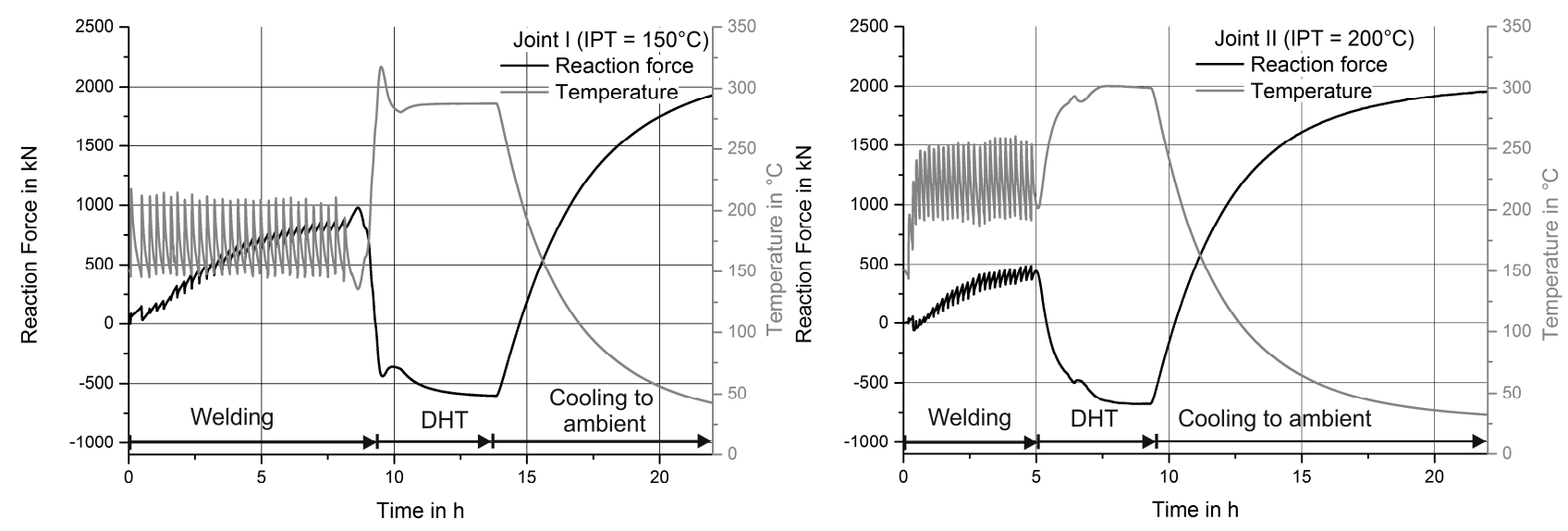

Fig. 3: Reaction force and temperature recorded during welding, DHT and cooling to ambient temperature for joint I (IPT $=150^{\circ} \mathrm{C}$, left) and joint II (IPT $=200^{\circ} \mathrm{C}$, right)

Bending moment. The large-scale test facility used in this study offers the possibility to differentiate between the forces measured in four independent positions around the joint (cp. Fig. 2 ). As the joints are fully restrained, distortion is virtually disabled. Pronounced excentricity of the forces is accumulated then as bending moment. Knowledge of the difference in forces between upper and lower side of the joint allows for determination of the bending moment occurring around the neutral axis of the test system. Fig. 4 shows the bending moments determined for joint I and joint II during welding, DHT and subsequent cooling to ambient temperature. Additionally, the temperature is included on the right axis.
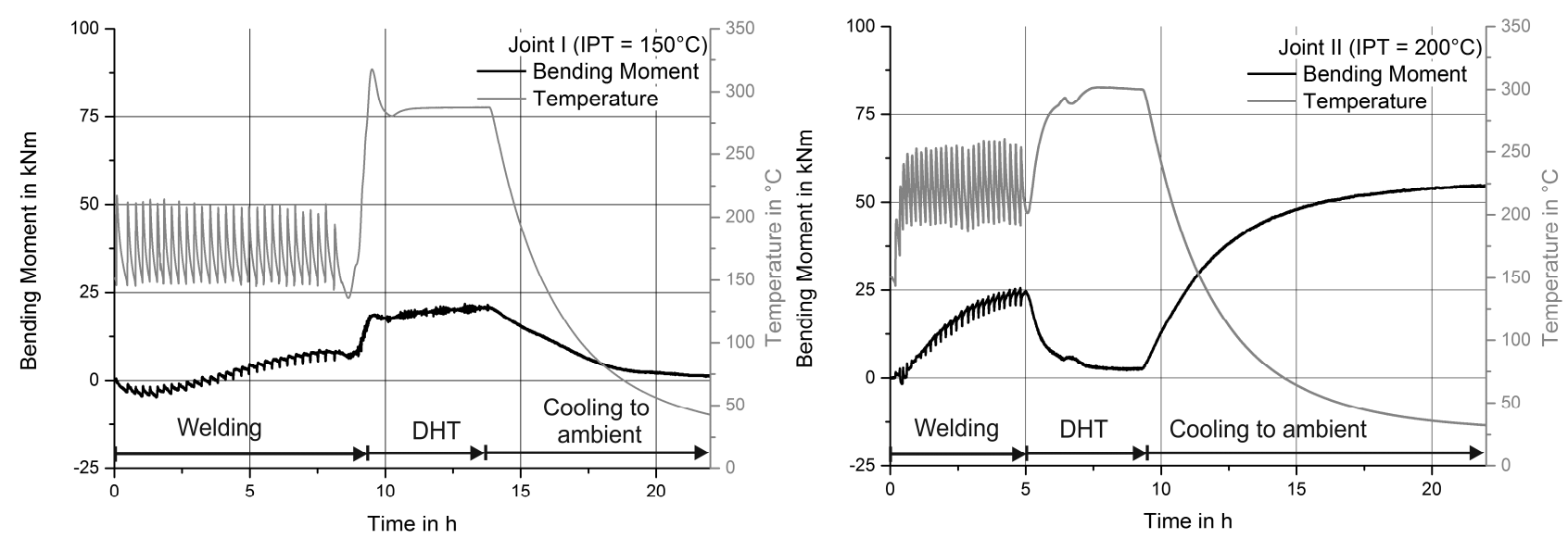

Fig. 4: Bending moments and temperature recorded during welding, DHT and cooling to ambient temperature for joint I (IPT $=150^{\circ} \mathrm{C}$, left) and joint II (IPT $=200^{\circ} \mathrm{C}$, right)

For joint II where the IPT was $200^{\circ} \mathrm{C}$, the characteristics are similar as for the reaction forces (cp. Fig. 3). That is, the moment is increased during the welding cycles. Then, DHT released the bending moment almost completely. Subsequent cooling to ambient temperature caused a steep increase of the bending moment to about $56 \mathrm{kNm}$. For joint I with IPT $=150^{\circ} \mathrm{C}$ the bending moment differed from this behavior during all stages of the test. While welding was characterized by comparatively low bending moments (negative values followed by positive ones) the DHT induced an increase of the moment. During cooling to ambient temperature the moment was released to an almost zero level. 
The reasons for the different behavior between both joints are to be found already during welding of the first passes. Fig. 5 gives a comparison of the bending moments registered in this early stage between joint I (left) and joint II (right). Welding with an IPT of $150^{\circ} \mathrm{C}$ (joint I) led to comparatively long shrinkage cycles, which are interrupted by the heat input when welding the subsequent pass. The first passes were located well below the neutral axis of the system. This resulted in higher shrinkage forces on the joint bottom side. It follows, that the bending moment was negative in this early stage of the welding cycle. After welding of the 5 th pass the trend decreased, as with increasing number of passes the center of gravity of the weld volume moved towards the neutral axis. As a consequence the bending moment turned into positive values. While any heat input tended to increase the bending moment, the shrinkage cycles led to a decrease.

When welding with a higher IPT (Fig. 5, right), the shrinkage cycles were interrupted earlier already at $200^{\circ} \mathrm{C}$. Hence, the development of high shrinkage forces at the root side of the joint was prevented. Instead, the accelerated weld build-up (above the center of gravity) resulted in a positive bending moment already during welding of the first passes. This trend continued with increasing number of passes. Contrary to joint I (lower IPT) any heat input during welding decreased the bending moment, while the shrinkage cycles tended to increase it.
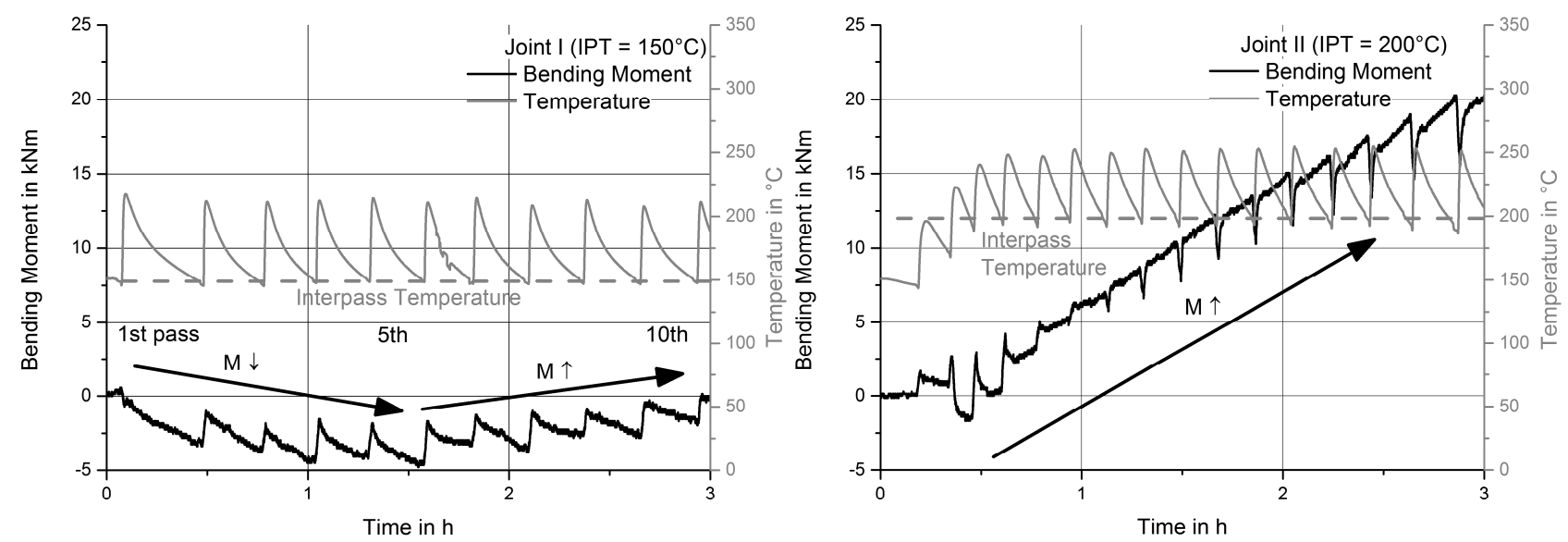

Fig. 5: Bending moments and temperatures during welding for joint $\mathrm{I}\left(\mathrm{IPT}=150^{\circ} \mathrm{C}\right.$, left $)$ and joint II (IPT $=200^{\circ} \mathrm{C}$, right)

Subsequently after finishing the last pass both joints were subjected to the DHT. Here the bending moment found in joint I (see Fig. 4 left) was increased to positive values. This is consistent with the observation that heat input during welding also tended to increase the bending moment (see Fig. 5 left). On the other hand, in case of joint II, the DHT decreased the bending moment as shown in Fig. 4 (right). As observed already during welding (see Fig. 5 right), the heat input tended to decrease the bending moment in this case. It follows, that for joint I a large bending moment was present during the heat treatment. On the other hand the bending moment disappeared for joint II.

After completion of DHT both joints cooled down to ambient temperature. The bending moment in joint I follows the temperature gradient, as shown in Fig. 4 (left). When cooling joint II the bending moment behaved opposite to the temperature.

Reaction stresses. It was demonstrated, that the reaction forces as well as bending moments were affected by the IPT. In order to estimate the resulting reaction stress in the samples the forces and moments may be simply related to the joints cross section. For that purpose it is assumed that the plates mid axis is coincident with the neutral axis of the test system. The total reaction stress in the upper plate surface was calculated following Eq. 1. The reaction force is divided by the plate cross section. The second term relates the bending moment to the elastic section modulus of the plate cross section. For reasons of simplicity the any excess weld metal was not considered here. Applying Eq. 1 for both welding scenarios the results shown in Table 5 can be calculated. It is obvious, that the overall load in the joint may be considerably affected by bending moments. In the present case a hundred times higher bending moment would result in an approximately four times 
higher reaction stress in weld transverse direction. Local residual stress determination by X-ray diffraction should clarify if this high stress level is in fact present in the specimen top surface.

$$
\sigma_{y}=\frac{F_{y}}{A}+\frac{M_{x}}{W_{x}}
$$

$\sigma_{\mathrm{y}} \quad-\quad$ reaction stress on top surface in weld transverse direction

$\mathrm{F}_{\mathrm{y}} \quad-\quad$ reaction force in weld transverse direction

A $\quad-\quad$ joints cross section

$\mathrm{M}_{\mathrm{x}} \quad$ - $\quad$ bending moment around the weld longitudinal axis

$\mathrm{W}_{\mathrm{x}} \quad$ - elastic section modulus around the weld longitudinal axis

Table 5: Overview of final reaction forces, bending moments and resulting stresses

\begin{tabular}{ccccc} 
Joint & $\begin{array}{c}\text { Interpass } \\
\text { temperature }\left[{ }^{\circ} \mathrm{C}\right]\end{array}$ & $\begin{array}{c}\text { Reaction force } \mathrm{F}_{\mathrm{y}} \\
{[\mathrm{kN}]}\end{array}$ & $\begin{array}{c}\text { Bending moment } \\
\mathrm{M}_{\mathrm{x}}[\mathrm{kNm}]\end{array}$ & $\begin{array}{c}\text { Reaction stress } \sigma_{\mathrm{y}} \\
{[\mathrm{MPa}]}\end{array}$ \\
\hline I & 150 & 2126 & 0.56 & 97 \\
II & 200 & 1982 & 56 & 404
\end{tabular}

Residual Stresses. The transverse residual stresses measured in the top surface of the individual joints are shown in Fig. 6. In order to avoid stress relaxation the joints were not removed from the test facility. Additionally to the residual stresses, the reaction stress level calculated for each joint (see Table 5) is included in Fig. 6. For both joints, the weld center was predominantly in compression, showing peak values up to $-200 \mathrm{MPa}$. Adjacent to the weld center the residual stresses became tensile. Here maximum values of approximately $400 \mathrm{MPa}$ were registered in case of joint II, while joint I showed just about $100 \mathrm{MPa}$.
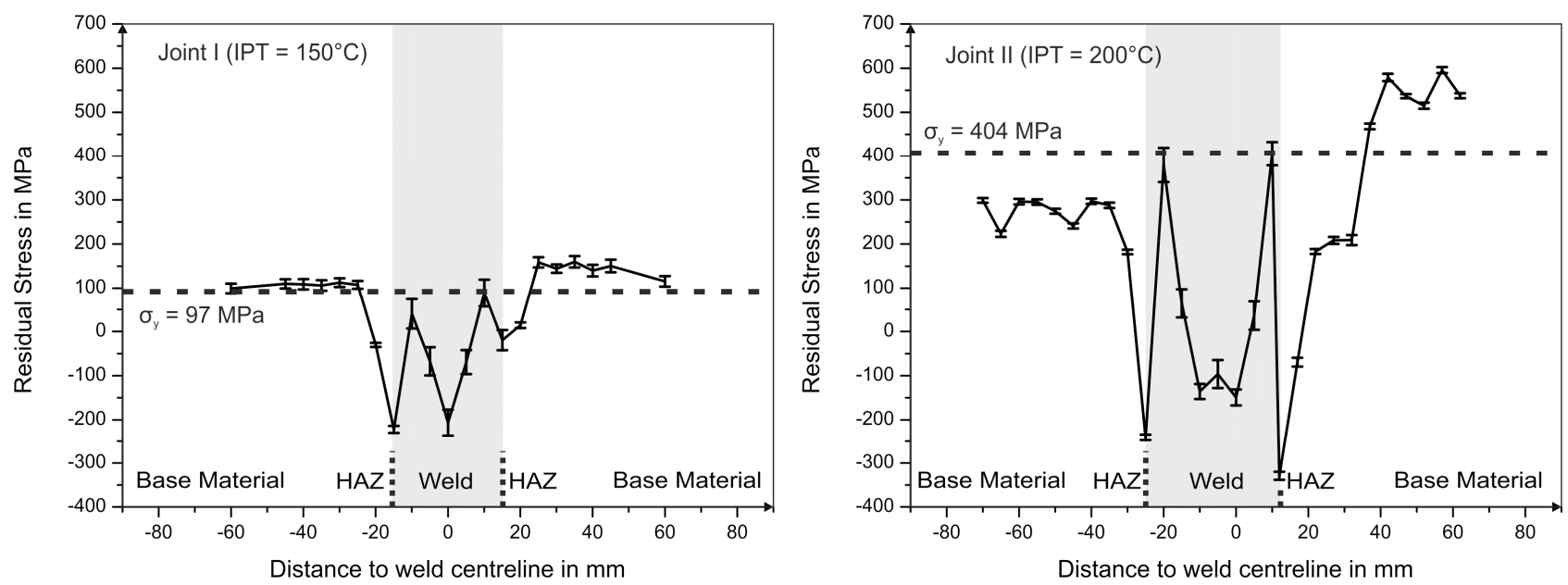

Fig. 6: Residual stresses and reaction stresses for joint I (IPT $=150^{\circ} \mathrm{C}$, left $)$ and joint II (IPT $=200^{\circ} \mathrm{C}$, right)

In the transition to the HAZ the residual stresses turned again into compression of up to -300 MPa. With higher IPT the residual stresses tended to form higher absolute levels. The outer HAZ and the base material were characterized by tensile residual stresses. While in case of joint I the residual stress level corresponds well with the estimated reaction stresses, the residual stress level in joint II does not match the estimated reaction stresses. Varying residual stress distributions were found on both sides of the weld which may induced by asymmetric bending. However, the residual stress peaks found in the weld are similar to the estimated reaction stresses. 


\section{Summary and Conclusions}

The present work dealt with the stress-build up during sub-merged arc multi-pass welding of thick sectioned plates taking into account forces and particularly bending moments. From this study, the following conclusions can be drawn. The reaction forces occurring in weld transverse direction show similar behavior in quality for two interpass temperatures investigated. Differences where observed for the bending moments. Therefore, in case of higher interpass temperatures the estimated reaction stresses were higher. In accordance to this, higher local residual stresses were found in the joint. When evaluating the residual stress state, additional to the well-known phenomena of shrinkage, phase transformation and quenching - which are mainly limited to the weld and HAZ - the bending moment should be considered individually in case of thick walled joints. As predictions are difficult, complex component tests seem to be a necessary tool. Future investigations are intended, to explore the observed phenomena in detail.

\section{References}

[1] R.H. Leggat, Residual stresses in welded structures, Int. J. Pres. Ves. Pip. 85 (2008) 144-151.

[2] T. Boellinghaus, T. Kannengiesser, M. Neuhaus, Effects of the Structural Restraint Intensity on the Stress Strain Build Up in Butt Joints, in: H. Cerjak, E. Kozeschnik H.K. Bhadeshia (Eds.), Mathematical Modelling of Weld Phenomena, Vol. 7, Verlag der Technischen Universität Graz, 2005, pp. 651-669.

[3] T. Lausch, T. Kannengiesser, M. Schmitz-Niederau, Multi-axial load analysis of thick-walled component welds made of 13CrMoV9-10, J. Mater. Process. Tech. 213 (2013) 1234-1240.

[4] T. Nitschke-Pagel, H. Wohlfahrt, Residual Stresses in Welded Joints - Sources and Consequences, Mater. Sci. Forum 404-407 (2002) 215-226.

[5] H. Wohlfahrt, Die Bedeutung der Austenitumwandlung für die Eigenspannungsentstehung beim Schweißen, Härterei Technische Mitteilungen 41 (1986) 248-257.

[6] P. Colegrove, C. Ikeagu, A. Thistlethwaite, S. Williams, T. Nagy, W. Suder, A. Steuwer, T. Pirling, Welding process impact on residual stress and distortion, Sci. Technol. Weld. Joi. 14 (2009) 717-725.

[7] P. Wongpanya, T. Boellinghaus, T. Kannengiesser, G. Lothongkum, Effects of preheating and interpass temperature on stresses in S 1100 QL multi-pass butt-welds, Weld. World 52 (2008) 7992.

[8] Y.C. Lin, J.Y. Perng, Effect of welding parameters on residual stress in type 420 martensitic stainless steel, Sci. Technol. Weld. Joi. 2 (1997) 129-135.

[9] A.F. Mark, J.A. Francis, H. Dai, M. Turski, P.R. Hurrell, S.K. Bate, J.R. Kornmeier, P.J. Withers, On the evolution of local material properties and residual stress in a three-pass SA508 steel weld, Acta Mater. 60 (2012) 3268-3278.

[10] T. Kannengiesser, T. Lausch, A. Kromm, Effects of Heat Control on the Stress Build Up during High-Strength Steel Welding under Defined Restraint Conditions. Weld. World. 55 (2011) 58-65.

[11] E. Macherauch, P. Müller, Das $\sin ^{2} \psi$ - Verfahren der röntgenographischen Spannungsmessung. Zeitschrift für angewandte Physik. 13 (1961) 305-312. 